\title{
Conceitos de "prática" no campo educacional: história conceitual e teoria das representações sociais em foco
}

\author{
Concepts of "practice" in the educational field: conceptual \\ history and theory of social representations in focus
}

Conceptos de "práctica" en el campo educativo: historia conceptual y teoría de las representaciones sociales enfoque

ANDRÉ AUGUSTO DINIZ LIRA (DiDa

LÚCIA VILLAS BÔAS

\section{Resumo}

Neste artigo pretendemos empreender uma reflexão sobre os conceitos de prática (social, educativa, pedagógica, docente) por meio da história conceitual e das contribuições possíveis advindas da Teoria das Representações Sociais (TRS). Analisamos, primeiramente, o debate sobre as práticas no campo científico educacional, a seguir, seus desdobramentos em obras de referência lexicográfica, e, por fim, as contribuições que emergem dos estudos da TRS. Para tanto, lançamos mão de uma pesquisa lexicográfica para apreender a narrativa semântica em desenvolvimento em obras de referência, tendo um corpus de 10 dicionários e 4 glossários técnicos de educação, produzidos no Brasil ou traduzidos para língua portuguesa, desde a década de 1970, com o intuito de considerar obras que tiveram maior circulação em nosso meio. Verificamos que os conceitos de prática social, prática educativa, prática pedagógica e prática docente se estabelecem, sobretudo, a partir da década 2000 e, embora se apresentem em diferentes perspectivas, notamos que ora se caracterizam por uma visão mais associada à transformação no contexto educacional, ora por um compromisso com a inteligibilidade dos processos ocorridos nesse âmbito. Esse trajeto sinaliza para os desafios e as lacunas

a Universidade Federal de Campina Grande (UFCG), Campina Grande, PB, Brasil. Doutor em Educação. Tutor do PET Pedagogia/CH/UFCG. e-mail: andreaugustoufcg@gmail.com

${ }^{\text {b } F u n d a c ̧ a ̃ o ~ C a r l o s ~ C h a g a s ~(F C C), ~ S a ̃ o ~ P a u l o, ~ S P, ~ B r a s i l . ~ D o u t o r a ~ e m ~ P s i c o l o g i a ~ d a ~ E d u c a c ̧ a ̃ o, ~ e-m a i l: ~}$ lboas@fcc.org.br 
no tocante ao entendimento dessas práticas, partindo de abordagens mais plurais e integradas do agir docente.

Palavras-chave: Prática docente. Representações Sociais. História conceitual.

\begin{abstract}
In this article we intend to undertake a reflection on the concepts of practice (social, educational, pedagogical, teaching) through conceptual history and possible contributions from the Theory of Social Representations (TRS). We analyze, first, the debate about practices in the educational scientific field, then, its consequences in lexicographic reference works, and, finally, the contributions that emerge from the studies of the TRS. To this end, we used a lexicographic research to apprehend the semantic narrative in development, in reference works, having a corpus of 10 dictionaries and 4 technical glossaries of education, produced in Brazil or translated into Portuguese, since the 1970s, in order to consider works that had greater circulation in our environment. We found that the concepts of social practice, educational practice, pedagogical practice and teaching practice were established, above all, from the 2000s onwards, and although they are presented in different perspectives, we note that now they are characterized by a vision more associated with the transformation in the educational context, as well as a commitment to the intelligibility of the processes that took place in this area. This path points to the challenges and gaps in terms of understanding these practices, based on more plural and integrated approaches to teaching.
\end{abstract}

Keywords: Teaching practice. Social Representations. Conceptual history.

\title{
Resumen
}

En este artículo pretendemos emprender una reflexión sobre los conceptos de práctica (social, educativa, pedagógica, docente) a través de la historia conceptual y las posibles contribuciones de la Teoría de las representaciones sociales (TRS). Analizamos, primero, el debate sobre las prácticas en el campo científico educativo, luego, sus consecuencias en los trabajos de referencia lexicográficos $y$, finalmente, las contribuciones que surgen de los estudios de la TRS. Con este fin, utilizamos una investigación lexicográfica para comprender la narrativa semántica en desarrollo, en trabajos de referencia, con un corpus de 10 diccionarios y 4 glosarios técnicos de educación, producidos en Brasil o traducidos al portugués, desde la década de 1970, para considerar obras que tuvieron mayor circulación en nuestro entorno. Descubrimos que los conceptos de práctica social, práctica educativa, práctica pedagógica y práctica docente se establecieron, sobre todo, a partir de la década de 2000, y aunque se presentan en diferentes perspectivas, observamos que ahora se caracterizan por una visión más asociada con la transformación en el contexto educativo, así como un compromiso con la inteligibilidad de los procesos que tuvieron lugar en esta área. Este camino apunta a los desafíos y lagunas en términos de comprensión de estas prácticas, basadas en enfoques de enseñanza más plurales e integrados. 
Palabras clave: Práctica docente. Representaciones sociales. Historia conceptual.

\section{Introdução}

Diversos autores das ciências humanas e sociais têm se dedicado, em contextos e em temporalidades variadas, à problemática relação entre teoria e prática e, por consequência, entre pensamento e ação, entre o dizer e o fazer. No âmbito da educação, isso também não é diferente. É possível vislumbrar sinais desse debate, em diversas matrizes teóricas que se perfilaram, se contrapuseram e se interpenetraram, ao longo da história da educação (CAMBI, 1999; MANACORDA, 2010; GAUTHIER, TARDIF, 2014; SAVIANI, 2018), ainda que essa reflexão tenha se desenvolvido mais nas últimas décadas (TARDIF, 2002; ALTET, 2011 apud ZANTEN, 2011).

Para além da enunciação quase sempre construída em termos de oposição entre teoria e prática, em diferentes marcos teóricos de referência, soma-se a isso, na literatura educacional, uma disputa relacionada aos qualificativos dessa "prática", como podemos observar nos termos "prática social”, "prática educativa", "prática pedagógica", "prática docente" e "prática de ensino", além da própria noção de "práxis". No campo educacional, essas noções se desdobraram em especificidades teóricas que demandam uma aproximação cuidadosa. Qualquer tentativa de classificação e de interpretação deve ser considerada pela compreensão dos obstáculos epistemológicos que permeiam o nosso próprio olhar (BOURDIEU; CHAMBOREDON; PASSERON, 1998).

Neste artigo, pretendemos empreender uma reflexão aproximativa dos conceitos de "prática" relativos à atividade docente por meio da narrativa semântica, fazendo, ainda, algumas incursões no âmbito da Teoria das Representações Sociais. Mobilizaremos aspectos pontuais da história conceitual, conforme elaborada por Koselleck (1992), na medida em que a narrativa semântica nos possibilita entender que “[...] a construção de um patrimônio conceitual não se dá de uma única vez, mas sim ao longo de uma história que envolve inúmeros pensadores e praticantes de um determinado campo de estudos" (BARROS, 2016, p. 25). Esse "fazer coletivo" 
manifesta-se permeado, no campo científico educacional, tanto por aspectos epistemológicos quanto políticos, devido às lutas pela imposição de legitimidade, em um espaço de forças desigual conforme os diferentes capitais em jogo (BOURDIEU, 2001). Por sua vez, a Teoria das Representações Sociais nos possibilita ampliar as reflexões iniciais traçadas com vistas ao desenvolvimento de futuras pesquisas, apoiando-nos em estudos que tratam da relação entre práticas e representações.

Assim, em um primeiro momento, apresentaremos o debate sobre os conceitos de prática por meio das noções de "prática social”, "prática educacional", "prática pedagógica" e "prática docente", levando em consideração as publicações que se tornaram mais reconhecidas e legitimadas em nosso meio, sobretudo por serem publicadas por grandes editoras do mercado nacional. A seguir, analisaremos os desdobramentos de seus usos em obras de referência lexicográfica, indicando sua pertença a uma narrativa semântica que alimenta determinadas matrizes de interpretação desse campo. Por último, consideraremos a discussão entre representações e práticas sociais e suas possíveis contribuições para a inteligibilidade das práticas docentes. Esse trajeto sinaliza para desafios e lacunas no tocante à compreensão das práticas docentes como objeto de reflexão teórica e de intervenção no cotidiano.

\section{Os conceitos de prática no campo educacional}

A discussão sobre os conceitos de prática na educação, incluindo seus qualificativos (social, educativa, pedagógica e docente) é relativamente recente do ponto de vista da narrativa histórica e ainda está longe de ser equacionada. Adensa-se, nesse âmbito, a discussão sobre o fazer, as finalidades, a justeza, a afetividade, a efetividade dessas práticas.

A noção de campo científico nos auxilia a compreender os diversos posicionamentos epistemológicos imersos em um amplo processo de legitimação/legitimidade dos agentes e das instituições participantes do jogo pela hegemonia interpretativa. Como destacou Bourdieu (2001), os autores dominantes em um campo estão nas instituições mais reconhecidas, tem a seu favor os lugares 
mais distintos para divulgação de suas ideias nas grandes editoras e recursos financeiros para pesquisas.

No campo científico educacional, um conjunto de autores reconhecidos, em nosso meio e internacionalmente, participou da construção da definição do lugar da prática na formação docente e na Pedagogia pelos conceitos de práxis, de prática social, educativa, pedagógica e docente. Apesar de diferenças no tocante ao encaminhamento teórico de suas obras, das ênfases e dos objetos de estudo investigados, alguns desses, sobretudo os brasileiros, partiram do materialismo histórico dialético e, em alguns casos, tiveram os mesmos autores como referência em suas primeiras reflexões.

Dermeval Saviani se esmerou no aprofundamento da leitura da história da educação pelas lentes do materialismo, considerando a práxis como um conceito crucial, sendo um autor dominante no campo dos produtores (YAMAMOTO, 1996). Libâneo, inclusive, reconheceu a importância de Saviani na construção do seu próprio pensamento sobre a pedagogia e a prática social (cf. FRANCO, 2012). Paulo Freire também utilizou o conceito de práxis, mas seguiu uma construção teórica própria, que se distanciou do materialismo clássico, aproximando-se de abordagens culturalistas e dialógicas. A obra de Freire enseja várias reflexões sobre a prática social, educativa e docente. A noção de práxis tornou-se chave para o desenvolvimento dos conceitos aqui analisados no Brasil, ainda que essa discussão esteja para além do escopo deste artigo.

Esse conceito-ponte, práxis, terminou por ser incorporado no conceito de "prática social", resguardando, assim, certo sentido político originário e a noção dialética que o termo enseja. Como veremos a seguir, "prática social" é um conceito que perpassa a obra de vários autores, servindo regularmente para delimitar: a) a construção de um coletivo docente; b) a ideia de transformação social; c) a definição da própria pedagogia como ciência. Já os conceitos de "prática educativa" e de "prática pedagógica" aparecem para alguns autores como intercambiáveis. Para outros, como distintos.

Libâneo (1998), procurando apresentar a especificidade da pedagogia, lança mão de diversas tentativas no intuito de cerceá-la conceitualmente, definindo seu objeto e a atividade do pedagogo. Esse autor sublinha que a pedagogia se ocuparia da 
educação intencional (referente às escolhas, valores e compromissos éticos) como uma "prática social", compreendida no quadro do funcionamento geral da sociedade. Em complemento, esclarece que as "práticas educativas não se dão de forma isolada das relações sociais que caracterizam a estrutura econômica e política de uma sociedade, estando subordinadas a interesses sociais, econômicos, políticos e ideológicos de grupos e classes sociais" (LIBÂNEO, 1998, p. 26). As práticas educativas, portanto, na perspectiva do autor, estão inclusas na conceituação mais ampla de prática social.

A discussão de Pimenta (1999) se desenvolveu na perspectiva da profissionalização docente, tendo por base a construção da identidade profissional. Isso se daria mediante a mobilização e a reinvenção dos saberes pedagógicos, sendo a "prática social" o ponto de partida e de chegada de "uma ressignificação dos saberes na formação de professores". Pimenta elucida que a "prática social de ensinar" se articula à didática, sendo necessário: "proceder a uma leitura crítica da prática social de ensinar, partindo de uma realidade existente, realizando um balanço de se fazer frente ao fracasso escolar" (PIMENTA, 1999, p. 25).

Convém observar o lugar de Pimenta nesse espaço de lutas distintivas. Pimenta publicou, entre outros, um livro que logo se tornaria referência na área, Professor Reflexivo no Brasil: gênese e crítica de um conceito (PIMENTA; GHEDIN, 2002), e também é organizadora da reconhecida coleção Docência em Formação da editora Cortez. O livro apresenta uma série de capítulos com uma vigorosa crítica à epistemologia da prática, pautado na compreensão de práxis, lançando mão também de vários autores da pedagogia crítica como José Gimeno Sacristán, Henry Giroux e José Contreras. Na apresentação da coleção Docência em Formação, a autora (2012) destaca a importância dos saberes da docência, da construção da identidade profissional e da necessidade de que os docentes ampliem a compreensão da educação como uma prática social complexa, ética e política, com vistas à superação do fracasso escolar. Nessa coleção, inclusive, publicou livros sobre a prática pedagógica (FRANCO, 2012; CHARLOT, 2014). A aproximação de Pimenta dos saberes da docência em sua trajetória acadêmica a faz se vincular mais à compreensão da educação como uma prática social, decorrendo daí a necessidade de uma vinculação contextualizada, ética e 
política do fazer pedagógico, em uma arregimentação teórica que ultrapassa a leitura da crítica marxista corrente.

Outra contribuição para a discussão específica sobre as práticas docentes foi apresentada por Franco (2012) ao problematizar abordagens de autores contemporâneos como Dermeval Saviani, José Carlos Libâneo, Selma Pimenta, Bernard Charlot e Philippe Meirieu. Após indicar os usos intercambiáveis dos conceitos de prática educativa e prática pedagógica, entendidos em muitas obras como sinônimos, Franco (2012) aponta para a necessidade de uma diferenciação entre esses dois termos. Segundo ela, enquanto as práticas educativas se direcionam para a concretização de processos educacionais, as práticas pedagógicas correspondem "a práticas sociais exercidas com a finalidade de concretizar processos pedagógicos” (FRANCO, 2012, p. 152). As práticas pedagógicas são intencionais, visam atender às expectativas de uma comunidade social, considerando o trabalho de um coletivo, atravessados por "relações de produção, culturais e ideológicas" (FRANCO, 2012, p. 152), visando a transformação social. Portanto, as práticas educativas estão presentes em uma variedade de situações e contextos, mas as práticas pedagógicas não, justamente pelas necessidades requeridas. A pedagogia como ciência deveria, portanto, analisar as diversas práticas educativas.

Além da produção brasileira na pedagogia, autores reconhecidos internacionalmente discutiram e contribuíram para a redefinição das leituras que, em nosso meio, se erigiram sobre a prática docente, notadamente a partir da década de 1990. Esse segundo conjunto de autores não pode ou não deveria ser compreendido como distanciados do pensamento pedagógico brasileiro. Pelo contrário, pois foi em movimentos de continuidade e de oposição que se firmaram e se afirmaram outras leituras no Brasil sobre a prática docente.

A editora Grupo A, através dos selos Penso e Artmed, tem publicado obras de Donald Schön, Philippe Perrenoud, José Gimeno Sacristán, Angel Pérez Gomez, Margerite Altet. A editora Vozes também tem importantes publicações de Maurice Tardif e Clermont Gauthier, entre outros. Contra Donald Schön e Philippe Perrenoud se erigiu uma forte crítica em solo brasileiro. O primeiro devido à Epistemologia da Prática e o segundo por causa da teorização sobre as competências e sobre as práticas reflexivas, ainda que esses aspectos não possam, de maneira alguma, restringir a obra 
desses dois autores (SCHÖN, 2003; PERRENOUD, 2002). As obras destes últimos autores foram lidas muitas vezes, até injustamente, pelas insígnias do tecnicismo e da alienação política.

A publicação da obra coletiva Formando Professores Profissionais pela Artmed, organizada por Lepold Paquay e demais autores (PAQUAY et al., 2001) foi crucial para compreender o lugar central da prática de ensino na formação e profissionalização docente pelas competências, saberes docentes e pelo habitus profissional. Apesar das diferentes nuanças dessas construções teóricas, as "práticas docentes" são referidas no contexto das "práticas de ensino", que podem ser vislumbradas em várias publicações, anteriores e posteriores, desse grupo de autores quanto à formação e à profissionalização docente (entre outros: GIMENO SACRISTÁN; PEREZ GOMÉZ, 1998; TARDIF, 2002, ALTET, 2017).

No quadro da prática docente, Meirieu (2008) discutiu amplamente sobre a tensão entre o dizer e o fazer na profissão. Charlot (2000, 2014) direcionou-se para as práticas educativas na sua relação com o saber, tendo progressivamente adquirido visibilidade no campo científico educacional, inclusive por sua atuação como professor visitante no Brasil. Altet $(2001,2017)$ analisa a prática docente a partir da observação das práticas de ensino em suas relações com a aprendizagem ${ }^{1}$.

Ao problematizar o ensino para a compreensão, Gimeno Sacristán e Perez Goméz (1998) apontam para a necessidade de intervir na escola, revisando a dimensão da prática docente em três grandes perspectivas: como atividade técnica, como atividade heurística/artística e como atividade ética. Quanto à perspectiva técnica, discutem a partir do modelo processo-produto, pela via de uma razão instrumental, que negligencia a subjetividade ou quer evitá-la a todo custo para que se atinja, então, a eficácia no ensino. Essa perspectiva conjuga, por um lado, a homogeneização das práticas docentes e, por outro, a sua individualização, impondo-se daí a ideologia do individualismo e a ênfase na competição. Em relação à perspectiva heurística/artística ${ }^{2}$, o que se destaca são os processos de criação e de transformação de significados, sublinhando-se os esquemas de interpretação em movimento, a necessidade de se conhecer o ponto de vista dos aprendentes, os processos de

\footnotetext{
${ }^{1}$ Retomaremos, no tópico seguinte, a obra dessa autora e também a de Perrenoud.

2 Os autores intercambiam esses termos.
} 
subjetivação e a experiência humana para movimentar as práticas pedagógicas. Por fim, o ensino na perspectiva da prática ética é compreendido como uma prática social em sua contingência histórica e espacial, vinculado a valores socialmente constituídos e incluídos, por exemplo, nas práticas curriculares. As atividades são compreendidas no tempo longo das aprendizagens, destacando-se as dimensões criadoras e inovadoras.

Tardif (2002) também apresentou sínteses inovadoras sobre a prática docente que possibilitam uma compreensão rica, multifacetada e plural dessa atividade e inclusive servem como grade de análise para pesquisas sobre o agir pedagógico. A primeira grande síntese que realiza enfoca a "prática de ensino" sob três aspectos de intervenção: a) como arte, tendo como maior expoente Schön; b) como técnica guiada por valores, que termina por dicotomizar a esfera da subjetividade e da objetividade, muito presente na Escola Nova; c) como interação no quadro do agir interativo e do dialogismo contemporâneo. Uma segunda síntese, mais completa, é também apresentada por esse autor (2002) seguindo uma grade de análise de seis grandes aspectos: atividades típicas na educação; esferas típicas na educação; caso ilustrativo; papel típico da educação; saber ou competência; modelo da prática educativa. Disso resultaram oito grandes abordagens das práticas de ensino, segundo o autor, sobre o agir docente: a) tradicional; b) afetivo; c) instrumental; d) estratégico; e) normativo; f) dramatúrgico; g) expressivo; h) comunicacional. Esses modelos do agir docente não podem ser concebidos como estanques, posto que são histórica e socialmente constituídos, perpassando as práticas pedagógicas docentes, inclusive produto da reflexão sobre a atividade cotidiana.

Faz-se necessário, no entanto, uma síntese desta parte. A forte influência do materialismo histórico e do conceito de práxis deu visibilidade a um outro conceito emergente no campo educacional, o de "prática social". A educação como uma das práticas sociais, no caso em tela, significa um agir intencional voltado para a transformação social. Todavia, outras teorias iriam se consolidar em nosso meio, voltadas mais para a prática de ensino, e se consubstanciariam nas chamadas “epistemologias da prática”. Retomaremos, a seguir, alguns desses pontos. 


\section{O conceito de prática em obras de referência lexicográfica de educação}

\section{Alguns apontamentos da pesquisa}

As obras de referência lexicográficas são veículos fundamentais para se entender a história dos conceitos em uma área, retratando, em suas ausências e presenças, em suas variações e regularidades, os embates em seu entorno. Essas obras atendem a particularidades de uma determinada fração de um campo social (científico, literário, artístico etc), na terminologia de Bourdieu (2001), ou de uma esfera discursiva, na terminologia de Bakthin (2016).

Lahlou (1996, p. 56), sublinhou que, por meio de suas definições, as obras de referência, como dicionários, apresentam um universo discursivo coerente, no qual a cultura se "coloca atrás das palavras". Na perspectiva da história conceitual, nem todas as palavras do léxico podem ser entendidas como um conceito científico, uma vez que se requer "certo nível de teorização e cujo entendimento é também reflexivo" (KOSELLECK, 1992, p. 2). Como observamos anteriormente, a década de 1990 foi fundamental para a consolidação de conceitos de prática no campo da educação. Os dicionários técnicos refletem tanto os conceitos de uma área retrospectivamente como aqueles em voga e até em movimentos progressivos de afirmação de identidade teórica, delimitando-se, assim, o campo conceitual.

Os dicionários técnicos [ou especializados], os glossários e os vocabulários são muitas vezes chamados de modo indistinto, referindo-se aos termos usados em uma determinada área de conhecimento (FROMM, 2004; BARBOSA, 2001). Tecnicamente, nos estudos lexicográficos são distintos utilizando-se de unidades-padrão distintas como a palavra, o vocábulo, o termo. O corpus da pesquisa, explicitado no Quadro abaixo, contou com 14 obras de referência técnicas em 
educação, sendo 10 dicionários e 4 glossários ${ }^{3}$. A escolha desse corpus escrito originalmente ou traduzido para a língua portuguesa teve por finalidade considerar obras que poderiam ter maior circulação em nosso meio.

Quadro 1 - Obras de referência lexicográfica consultadas

ANTUNES, C. Glossário para Educadores(as). Petrópolis: Vozes, 2001.

ARENILLA, L. et al. Dicionário de pedagogia. 2. ed. rev. e aument. Lisboa: Instituto Piaget, 2013.

CALDART, R. S.; PEREIRA I. B.; ALENTEJANO, P.; FRIGOTTO, G. (Orgs.). Dicionário da Educação do Campo. Rio de Janeiro, São Paulo: Escola Politécnica de Saúde Joaquim Venâncio, Expressão Popular, 2012.

CALDEIRA, A. M. S.; ZAIDAN, S. Prática pedagógica. In: OLIVEIRA, D. A.; DUARTE, A. M. C.; VIEIRA, L. M. F. Dicionário: trabalho, profissão e condição docente. Belo Horizonte: UFMG/Faculdade de Educação, 2010. CDROM Disponível na internet em: http://gestrado.net.br/pdf/328.pdf Acesso em: 15 maio 2020.

DUARTE, S. G. Dicionário Brasileiro de Educação. Rio de Janeiro: Edições Antares, Nobel, 1986.

FOULQUIÉ. Dicionário da Língua Pedagógica. Lisboa: Livros Horizonte, 1971.

LUZ, G. Prática Pedagógica. In: SOUZA, J.; GUERRA, R. Dicionário Crítico de Educação. Belo Horizonte: Dimensão, 2014.

MOROSINI, M. C. Glossário. In: MOROSINI, M. C. (Org.). Enciclopédia de Pedagogia Universitária. Porto Alegre: FAPERGS/RIES, 2003. p. 295-434.

MOROSINI, M. C. Glossário. In: MOROSINI, M. C. (Org.). Enciclopédia de Pedagogia Universitária. Glossário, v. 2. Brasília: INEP/RIES, 2006.

PEREIRA, I. B.; LIMA, J. C. F. Dicionário da educação profissional em saúde. 2. ed. rev. ampl. Rio de Janeiro: EPSJV, 2008.

QUEIROZ, T. D. Dicionário Prático de Pedagogia. São Paulo: Rideel, 2011.

STRECK, D. R.; REDIN, E.; ZITKOSKI, J. Dicionário Paulo Freire. Belo Horizonte: Autêntica, 2008.

VASCONCELOS, M. L.; BRITO, R. H. P. Conceitos de educação em Paulo Freire: glossário. Rio de Janeiro: Vozes; São Paulo: Mack Pesquisa, 2014.

ZANTEN, A. Van. Dicionário de Educação. Petrópolis, Vozes: 2011.

Fonte: Os autores (2020).

Sobre o corpus acima, salientamos que os dicionários e vocabulários de organização coletiva apresentavam os termos utilizados por meio da autoria dos seus colaboradores, que serão destacados ao longo deste texto. Sublinhamos também que a Rede Sub-brasileira de Investigadores da Educação Superior produziu a Enciclopédia de Pedagogia Universitária, vol. 1 e vol. 2 (MOROSINI, 2003; MOROSINI, 2006). O volume 1 apresenta um conjunto de textos que retrata a realidade da profissão docente

\footnotetext{
${ }^{3}$ Vale salientar que as enciclopédias de Pedagogia Universitária organizadas por Morosini (2003, 2006), volume 1 e 2, respectivamente contêm (volume 1) ou mesmo são um glossário (volume 2). 
universitária brasileira e um pequeno glossário. $\mathrm{O}$ volume 2 dessa enciclopédia apresenta apenas um glossário, porém bem mais denso. As definições do 1 (prática pedagógica, prática pedagógica dialógica, epistemologia da prática profissional) se encontram basicamente repetidas no volume 2, mas há o acréscimo de outras definições e discussões teóricas (sobre prática, relação teoria-prática, prática educativa, ação educativa). Preferimos, aqui, lançar mão mais do volume 2 dessa obra coletiva, por ser mais completa do ponto de vista conceitual. Isso já nos leva a uma primeira constatação: o refinamento conceitual no período considerado.

\section{O desenvolvimento do conceito de prática retratado em obras de referência lexicográfica}

Observamos, no corpus analisado, que os conceitos de prática (social, educativa, pedagógica, docente) são incorporados às obras de referência lexicográfica apenas a partir da década de 2000. Ainda que algumas dessas obras, mesmo atuais, ainda não os tenham incorporado (ARENILLA, 2013; QUEIROZ, 2011; CALDART et al., 2012; PEREIRA; LIMA, 2008). Em seu Dicionário da Lingua Pedagógica, Foulquié (1971) não apresenta nenhum conceito sobre prática e seus correlatos. O Dicionário Brasileiro de Educação, de Duarte (1986), apresenta o conceito sobre prática profissional em um quadro genérico sem vinculação com a docência. O vínculo é com o profissional técnico, destacando-se as habilidades motoras no quadro das profissões relacionadas ao tecnológico.

Como afirmamos, as obras de referência técnicas podem retratar retrospectivamente o movimento histórico de conceitualização, inclusive, pondo em relevo a obra de determinados autores. Cientes disso, analisamos um dicionário e um vocabulário sobre a obra de Paulo Freire. Afirmamos ainda que Freire se utilizou em sua vasta obra do conceito de práxis, mas trilhou uma caminhada própria afastandose do materialismo clássico. Acrescentamos também que lançou mão várias vezes do conceito de prática sob a perspectiva da prática social e da prática educativa (FREIRE, 1996; 2011; 2018), em uma discussão ampla e dialética, perpassando do trabalhador ao estudante, da escola à sociedade e desta às estruturas do poder instituído, da 
subjetividade à materialidade das relações. Nas obras de referência analisadas, o conceito de práxis é destacado tanto por Streck, Redin e Zitkoski (2008) quanto por Vasconcelos e Brito (2014). O conceito de prática educativa é destacado apenas por Vasconcelos e Brito (2014, p. 156-157) no sentido de “[...] a capacidade do educador somar conhecimento, afetividade, criticidade, respeito, ação e, em conjunto, com o seu educando, concorrer para a transformação do mundo". As práticas educativas envolvem uma série de aspectos distintos, mas que visam articulação e ação conjuntas pelo educador e educando, objetivando a transformação social.

Destaca-se, no âmbito da obra freirena, que a inventividade e a criticidade do autor ganham relevo para que a prática educativa seja concebida de um modo integrado, holístico e transformador, não se restringido à atividade docente propriamente dita. Reduzir a prática educativa à docência e à escola seria muito limitador nesse edifício teórico. Por fim, a obra de Paulo Freire irá influenciar diretamente o conceito de prática pedagógica dialógica exposto por Fernandes e Grillo (2006 apud MOROSINI, 2006) mais adiante.

Outros dicionários com uma perspectiva mais panorâmica e sistematizadora, do ponto de vista da revisão teórica, sinalizam para vários enfoques sobre os conceitos de prática na educação. Por um lado, são unânimes em criticar os usos de uma abordagem que denominam de positivista (CALDEIRA; ZAIDAN, 2010; LUZ, 2014) ou behaviorista, do produto-processo das práticas (ALTET, 2011 apud ZANTEN, 2011). Por outro lado, apresentam e se inclinam para determinadas filiações teóricas sobre os conceitos de prática. Sumariar esses posicionamentos é fundamental.

Caldeira e Zaidan (2010), apresentando o termo prática pedagógica no Dicionário: trabalho, profissão e condição docente, indicam que diferentes sentidos e significados podem emergir ao se considerarem as perspectivas teórico-metodológicas adotadas, discutindo as abordagens que denominaram de positivista, interpretativa e histórico-crítica ou dialética. Depreende-se que a perspectiva positivista é, em linhas gerais, emoldurada pelo cartesianismo, seguindo-se o cientificismo empirista e aplicacionista, em uma matriz filosófica realista. A perspectiva interpretativa da prática pedagógica é apresentada vinculando-se aos processos cognitivos de interpretação e de intencionalidade humanas, considerando-se a troca 
bidirecional em relação às ideias e as exigências das práticas de cada situação. Nesse sentido, em nossa opinião, poderia essa perspectiva se chamar de uma abordagem construtivista. Por último, a perspectiva histórico-crítica e dialética, à qual as autoras dedicam mais atenção, põe em relevo a dimensão histórica, política e tensional da prática pedagógica, desdobrando-se a necessidade de uma atuação que seja transformadora da sociedade. Essa abordagem segue, em linhas gerais, perspectivas teóricas educacionais de matriz crítica. Os textos e os autores que Caldeira e Zaidan (2010) têm como referência para discutir o termo prática pedagógica sob o que denominam de abordagem interpretativa e abordagem histórico-crítica e dialética não são do campo educacional. A reflexão se tece no âmbito da filosofia da ciência e da sociologia.

Luz (2014), no Dicionário Crítico de Educação, questiona também a perspectiva positivista da prática pedagógica. A autora advoga pela intencionalidade para a definição da prática pedagógica, levando em consideração autores do campo educacional brasileiro e internacional de matrizes epistemológicas distintas, tais como o materialismo dialético e a perspectiva pós-estruturalista. Como norte comum, talvez esteja justamente a abordagem crítica dos diferentes posicionamentos. Por outro lado, evidencia-se mais a leitura pós-estruturalista na qual a prática pedagógica poderia servir ao questionamento do currículo, levando em conta a inventividade de práticas estratégicas de política cultural. Ao mesmo tempo, a autora também se referenda em Schön na compreensão do paradigma do professor reflexivo. Ampliam-se aqui, de todo modo, as possibilidades interpretativas.

Ao expor os elementos básicos desta pesquisa, já discorremos sobre os glossários da Rede Sub-brasileira de Investigadores da Educação Superior, organizados em dois volumes por Morosini (2003; 2006), sinalizando que iríamos nos utilizar dos conceitos do volume 2. Essa obra coletiva é crucial para que se entenda o refinamento ou desenvolvimento conceitual, nessa narrativa semântica, sobre a prática docente.

A “prática”, nessa obra coletiva, é conceituada como uma "experiência vivida no contexto das vivências cotidianas que produz conhecimentos e experiências" (FERNANDES; GRILLO apud MOROSINI, 2006, p. 442) e são acrescidas várias observações em nota como "um saber possível na espera de conceituação", dinâmico 
e provisório, situado e não reduzido a uma aplicação. Ao lançar mão de Tardif, destaca-se a complexidade desse saber-fazer, que seria mais amplo do que o conhecimento discursivo. A “relação teoria-prática” é concebida para além da visão aplicacionista que reduz a prática a uma aplicação da teoria, definida, então, como um "movimento que interjoga um conjunto de componentes referidos às práticas dos sujeitos intervenientes no ato pedagógico, em que o conteúdo mediatiza essas práticas e as estratégias fazem possível o contexto da realização" (FERNANDES; GRILLO apud MOROSINI, 2006, p. 443), ressaltando-se que ambas devem ser consideradas como elementos fundantes da apropriação da totalidade.

A definição de "prática educativa" e "prática pedagógica" se aproximam. A "prática educativa" é compreendida como "ação orientada e plena de sentido que se desenvolve com objetivos pedagógicos, em que o sujeito tem um papel fundamental como agente, mesmo incluído na estrutura social" (FERNANDES; GRILLO apud MOROSINI, 2006, p. 444), lançando-se mão de Gimeno Sacristán para fazer referências de que elas devem ser compreendidas ainda mediante as interpretações que os agentes constroem em suas ações no mundo, sendo "ainda uma unidade de análise apropriada para entender a extensão e o enlace da iniciativa subjetiva com a ação social que envolve crenças coletivas e marcos institucionalizados" (FERNANDES; GRILLO apud MOROSINI, 2006, p. 444). Assim, a "prática pedagógica" é apresentada como uma:

"[...] prática intencional de ensino e de aprendizagem, não reduzida à questão didática ou às metodologias de estudar e de aprender. Notas: articulada a uma educação como prática social e ao conhecimento como produção histórica e cultural, datado e situado, numa relação dialética e tensionada entre prática-teoria-prática, conteúdo forma, sujeitos-saberes-experiências e perspectivas interdisciplinares." (FERNANDES; GRILLO apud MOROSINI, 2006, p. 447)

É importante sublinhar que a definição acima conjuga elementos das perspectivas de cunho materialista dialético, tal como visto anteriormente, mas também o escopo das obras que focalizam os "sujeitos-saberes-experiências e perspectivas interdisciplinares" (FERNANDES; GRILLO apud MOROSINI, 2006, p. 447) em sua construção. Essas confluências teóricas, já observadas na introdução deste artigo, não devem passar despercebidas, pois sinalizam para múltiplas perspectivas na construção da narrativa semântica que compõe também a história 
conceitual. Acrescenta-se, por fim, o conceito de "prática pedagógica dialógica" concebido como: prática caracterizada pela aprendizagem do professor com seus alunos. Professores e alunos aprendem que o compromisso da parceria é fundamental em uma relação humana horizontal, que não exclui do professor a responsabilidade de direção do processo de ensinar e aprender nem exime o aluno da responsabilidade de ultrapassar os limites de sua prática, recriando o espaço-tempo da reflexão e da cultura em relações democráticas e éticas.

A inserção do termo, da definição e das notas sobre "prática pedagógica dialógica” consolida um conjunto de perspectivas de matriz dialógica que, no Brasil, deve muito à obra de Paulo Freire. A matriz freireana da compreensão prática pedagógica dialógica é evidente na conceituação, inclusive é referenciada pelas autoras, diferentemente de abordagens mais atentas ao dialogismo na trilha dos estudos da linguística.

De todos os dicionários analisados, a obra organizada por Agnès van Zanten (2011) é, de longe, a mais complexa ao apresentar dois termos associados às práticas docentes: "professores (práticas profissionais dos professores)" escrito por Marguerite Altet (ALTET, 2011 apud ZANTEN, 2011); e "pesquisas e práticas pedagógicas”, escrito por Philippe Perrenoud (ALTET, 2011 apud ZANTEN, 2011). Altet apresenta a prática docente sob duas grandes abordagens: as que enfatizam as atividades em sala de aula e as que consideram a prática profissional docente sob múltiplas dimensões (instrumental, técnica, relacional, contextualizada, temporal, afetiva e psicossocial).

Altet vincula a prática docente à prática de ensino, em uma dimensão plural na qual se destacam abordagens complementares para se entender os processos em jogo, “[...] na confrontação de quadros teóricos diferentes (didático, sociológico, clínico, análise das interações docente/aprendiz, interações linguísticas intersubjetivas)" (ALTET, 2011 in: ZANTEN, 2011, p. 653), na qual se privilegiam nas pesquisas as práticas efetivas e não apenas os discursos sobre as práticas. Essa abordagem é denominada de interacionista e dela participam diversos grupos de pesquisa internacionais, destacando-se, entre outros aspectos, que a prática docente não pode ser compreendida como uma aplicação de métodos, enfocando-se as pesquisas compreensivas e explicativas, em detrimento de abordagens prescritivas da docência. 
A contribuição de Perrenoud, na obra supracitada, está em discutir a problemática da efetividade das práticas pedagógicas e as resistências em se pensar sobre essa necessidade, os saberes e as competências da docência, que devem se colocar a serviço de uma inteligência em ação ou, em outras palavras, na própria intervenção educativa (PERRENOUD, 2011 apud ZANTEN, 2011). Em outras publicações do autor é fundamental que se entenda que a "prática pedagógica reflexiva" se manifesta em várias dimensões processuais e contextualizadas, conscientes e inconscientes/irrefletidas, que o conceito de habitus enseja, para além da racionalidade técnica (PERRENOUD, 2001; 2002). Isso Perrenoud faz seguindo a trilha de Pierre Bourdieu, mas aplica o conceito de habitus na dinâmica da formação e profissionalização docentes.

Em síntese, podemos perceber que os conceitos de prática(s) se vincularam, em um primeiro momento de consolidação no Brasil no campo pedagógico, pela matriz histórico-dialética. Posteriormente, matrizes diversas foram sendo integradas, tais como as construtivistas (ou interpretativas), a pós-estruturalista e, com mais força, as denominadas "epistemologias da prática" juntamente com a discussão sobre os saberes, as competências da docência e a experiência no fazer docente. Essa caminhada, vale salientar, dá visibilidade a uma narrativa semântica na qual os conceitos de prática vinculados à atividade docente desenvolvem-se por refinamentos teóricos e investigativos.

Em que pesem essas disputas conceituais, é possível observar que as práticas, sejam elas qualificadas como pedagógicas e/ou como educacionais, são entendidas como construções sociais (DUPRIEZ; CHAPELLE, 2007), ou seja, compostas de representações e atitudes que são mutuamente geradas, construídas em interações com seu ambiente institucional, social e intelectual. Em relação a esse ponto, as discussões entre práticas sociais e representações sociais apresentam elementos que podem contribuir com a inteligibilidade das práticas docentes, como tentaremos mostrar a seguir.

\section{Prática no âmbito da teoria das representações sociais: alguns apontamentos}


No âmbito da psicologia, ainda que se reconheça uma situação análoga ao campo educacional na medida em que diferentes definições de prática coexistem com distintos qualificativos como, por exemplo, "prática grupal”, "prática comunitária", "prática cotidiana", "prática sociocultural", as práticas são mais comumente qualificadas como "práticas sociais", sobretudo em se tratando da perspectiva da teoria das representações sociais. É de Jodelet (1989, p. 36) a definição mais consensual acerca desse último conceito: "forma de conhecimento, socialmente elaborada e compartilhada, que tem um objetivo prático e concorre para a construção de uma realidade comum a um conjunto social".

A relação entre prática e representações aparece já em uma definição anterior da autora em que as representações são apresentadas como uma forma de conhecimento socialmente elaborado e compartilhado com o objetivo de “compreender e explicar os fatos e ideias que povoam nosso universo de vida ou que nele surgem, atuar sobre e com as pessoas, situar-nos em relação a elas, responder às perguntas que nos coloca o mundo, saber o que significam as descobertas científicas e o devir histórico para a conduta de nossa vida [...], em outros termos, trata-se de um conhecimento prático da realidade" (JODELET, 1984, p. 360, grifos apostos) ${ }^{4}$.

Segundo Abric (1994), também é dessa autora o conjunto de estudos mais completo das relações entre representações e práticas sociais, indicando a indissociação entre representação, discurso e prática.

Em que pese essa consideração, a relação entre representações e práticas ainda está longe de ser equacionada, tanto no plano teórico como no metodológico, como apontam os estudos de Sá (1994), Rouquette (1998), Almeida, Santos e Trindade (2000), Campos (2003), Wolter e Sá (2013) e, mais recentemente, Lima e Santos (2017).

Em uma síntese, sobretudo das pesquisas realizadas pelo grupo do Midi desde a década de 1980, Wolter e Sá (2013) mostram três eixos de discussão acerca da relação entre práticas e representações sociais. O primeiro deles refere-se, sobretudo, aos trabalhos desenvolvidos até a década de 1980 que centraram a problemática nas

\footnotetext{
${ }^{4}$ Vale lembrar aqui a famosa frase de Faucheux e Moscovici: "A psicologia social, como ciência e prática, é, indiscutivelmente política: ela tem um alcance político... " (1971, p. 63, grifos apostos). 
representações sociais como gerenciadoras das práticas; depois, na década de 1990, as pesquisas se direcionaram para a discussão da transformação das representações a partir das práticas; já no final dos anos noventa e início dos anos 2000, surge uma nova caracterização das práticas, sobretudo, a partir dos trabalhos de Rouquette (1998) quando este afirma que as representações sociais são uma condição das práticas e estas, um agente de transformação das representações. Ou seja, elas não mantêm entre si nem uma relação de equivalência nem de reciprocidade; antes engendram-se mutuamente (ABRIC, 1994).

Rouquette (1998), partindo da constatação da polissemia da noção de prática, indica que esta abrange ao menos dois aspectos: "a realização de uma ação (conduta efetiva) e a frequência (ou, correlativamente, a familiaridade para o sujeito) dessa realização”.

A ação, segundo ele, apresenta duas dimensões: as maneiras de fazer e as consequências percebidas desse fazer. Ao se referir à influência das práticas sobre as representações, Rouquette (1998) busca ainda delimitar algumas de suas características. São elas: 1) prática como passagem ao ato; 2) prática como recorrência; 3) prática como modo de fazer; 4) prática como "cálculo" (intencionalidade da ação).

De modo geral, os estudos educacionais que se fundamentam na teoria das representações sociais não têm levado em conta esses aspectos, difíceis de serem operacionalizados no âmbito das pesquisas (WOLTER; SÁ, 2013), mas que, com certeza, contribuiriam não somente para um olhar mais inteligível acerca das práticas de modo geral, como também se constituiriam como uma espécie de garantia contra a possibilidade de qualificar como representação social transmissões discursivas incidentais, ou seja, descrições de representações que são prováveis, mas que não emergem da vida social cotidiana daqueles que supostamente as utilizam e as transmitem (SÁ, 1994). Segundo o autor:

Tudo acontece como se o conceito pudesse, por si só, assegurar a legitimidade dos resultados da pesquisa, desde que a pesquisa seja chamada de estudo de representação social, e embora o objeto estudado não esteja de fato ligado a um fenômeno de representação social. Na verdade, não basta utilizar o conceito; é preciso verificar primeiro se o fenômeno em questão se enquadra no conceito. Há, portanto, uma justificativa na forma de uma proibição no campo da pesquisa sobre especulações relativas a representações "virtuais", ou seja, sobre suposições quanto à existência do fenômeno em relação a "objetos de representação" dificilmente possíveis. Em outras palavras, seria 
sempre aconselhável verificar se tal objeto de conversa está, até certo ponto, incluído em alguma forma de prática social consistente, antes de atribuir ao discurso sobre esse objeto as prerrogativas dos fenômenos representacionais (SÁ, 1994, p. 43).

Há ainda um outro aspecto que merece ser mencionado quando se pensa a relação entre práticas e representações. Do ponto de vista metodológico, os instrumentos mais usados no âmbito da teoria das representações sociais, sobretudo no contexto educacional, são instrumentos interrogativos e/ou associativos que focam nas práticas autorrelatadas e não nas práticas efetivas. As metodologias de coleta de dados utilizadas muitas vezes permanecem inadequadas para uma percepção mais precisa e multifacetada dos fenômenos estudados.

Some-se a isso o alerta de Abric (1994) de que não se pode dissociar representação, discurso e prática, pois eles estão sempre em relação, como um todo, contribuindo para formar o que ele denomina de sistema representacional. Nesse quesito, importa destacar que Jodelet (2005), em seu estudo sobre a loucura, por exemplo, mostra como algumas práticas trazem à tona aspectos da representação que não são verbalizados, evidenciando a necessidade de se considerarem os discursos e os atos, algo que será depois resgatado por Abric (2005) em torno da ideia da zona muda das representações sociais.

Abric (1994) destaca outros três fatores que têm um forte impacto tanto nas representações sociais como nas práticas. São eles: fatores culturais que atuam como matrizes culturais de interpretação das práticas; fatores ligados aos sistemas de normas e valores que intervêm como elementos de negociação entre práticas e representações; fatores ligados à atividade dos sujeitos, tais como as atividades de decodificação, sistemas de expectativas, antecipações e categorizações que associam representações às práticas.

O entendimento de prática na teoria das representações sociais, devido à necessidade de compreender os sujeitos em seus mundos de vida, se erige sobre o entendimento compartilhado do senso comum, nas múltiplas relações possíveis entre práticas e representações. As representações sociais compreendidas com saber coletivamente reproduzido e produzido dinamicamente sobre objetos relevantes do mundo social. Essa ideia se aproximaria mais da perspectiva heurística/artística exposta por Gimeno Sacristán e Perez Goméz (1998) e da perspectiva interpretativa 
delineada por Caldeira e Zaidan (2010) de prática educativa, sobretudo por se pautarem em leituras mais compreensivas do pensamento dos docentes e da ação pedagógica.

\section{Considerações finais}

O interesse pela noção de "prática", bem como os inúmeros qualificativos que a ela são associados, parece corresponder à mudança de ênfase das estruturas e processos globais para as relações no nível "micro" da vida cotidiana e que acompanha as ciências humanas e sociais em geral (JODELET, 2009).

Nesse contexto, a discussão e a análise das práticas no campo educacional vêm se tornando instrumento privilegiado na formação docente, embora nos pareça que ainda cabe nos questionar o que se está buscando ao estudá-las.

$\mathrm{Na}$ breve análise que realizamos aqui sobre a polissemia do conceito de práticas e a constituição de sua narrativa semântica no campo educacional, observamos duas tendências: uma que se refere àqueles estudos que buscam um conhecimento "para" a prática; e outra, que busca um conhecimento "sobre" a prática. Até certo ponto, isso poderia ser explicado, no primeiro caso, em termos de uma abordagem crítica e política, ainda que prescritiva, mesmo que voltada para a transformação social; e, no segundo caso, uma abordagem mais compreensiva do(s) sujeito(s).

Da primeira vertente, decorre um dever ser e um dever agir moldado por interpretações do quadro social. $\mathrm{Na}$ segunda vertente, ou seja, aquelas que buscam um conhecimento sobre a prática, a postura é de compreensão com o intuito de descrever o que ocorre no campo educacional. Não se trata, portanto, de entender para transformar: trata-se de saber o que é para conhecer a realidade, antes de saber o que é desejável para saber o que deve ser, e antes de saber o que deve ser feito para alcançar o desejável (HADJI; BAILLÉ, 1998).

Dessa breve discussão apresentada aqui acerca da narrativa semântica da prática no campo educacional e das possíveis contribuições da teoria das representações sociais gostaríamos de reter os seguintes aspectos: 
- O estudo das práticas docentes pressupõe a consideração do sujeito que as implementa e as condições dessa implementação;

- As práticas são contextualizadas e estão ligadas a uma multiplicidade de variáveis pertencentes aos contextos dos atores em constante mudança, não podendo, portanto, ser reduzidas aos fatores pessoais dos professores;

- A prática se constrói em situação. Os estudos em representações sociais têm indicado que a produção de saberes se encontra associada à produção de ação e de intervenção. Aprofundar nessa combinação pode ser um terreno fértil para a aproximação de pesquisas que articulem produção de saber, intervenção e parcerias. Isso pode também aportar uma contribuição para evidenciar as relações entre práticas e representações;

-Elas supõem mais que "aplicação". Ou seja, a formação docente está recheada de saberes formalizados cada vez mais sofisticados e complexos, enquanto os espaços destinados às práticas têm mantido sua concepção simplista que identifica a prática com o fazer e com a "aplicação" desse saber, contribuindo para a manutenção da polarização entre teoria e prática;

- Necessidade de articulação entre representação, discurso e prática. As práticas não podem ser reduzidas ao que pode ser observado. Atos, sequências de atos testemunham uma prática, mas isto não é suficiente para descrevê-la, muito menos para pensar sobre ela. Também não podem ser apreendidos apenas através do discurso e das declarações dos atores.

Ainda que se observem tentativas, no âmbito da formação e profissionalização docentes, de associação entre formação teórica e espaços de prática, isso segue sendo um problema difícil de superar:

las prácticas profesionales suelen concebirse como espacios destinados al hacer, mientras que los otros espacios curriculares de la formación - al estructurarse casi exclusivamente a partir de conocimientos formalizados - se conciben como espacios actuales de formación. (ALLIAUD, 2017, p. 67).

Para Altet (2003), estamos ainda distantes de possuir um corpo teórico robusto e validado que possa ser reconhecido enquanto teorias da prática docente e de seus 
processos característicos. Afinal, como afirma Latour (2011, p. 131), “em teoria, as teorias existem; mas, na prática, não. Isso é o que as torna tão difíceis de estudar”.

\section{Referências}

ABRIC, J.-C. La recherche du noyau central et de la zone muette des représentations sociales. In: ABRIC, J-C. (Org.). Méthodes d'étude des représentations sociales. Saint-Agne: ÉRÈS, 2005. p. 59-80.

ABRIC, J.-C. Pratiques sociales, représentations sociales. In: ABRIC, J.-C. (Org.). Pratiques sociales et représentations. Paris: Presses Universitaires de France, 1994. p. 217-238.

ALLIAUD, A. Los artesanos de la enseñanz̧a. Buenos Aires: Paidós, 2017.

ALMEIDA, A.; SANTOS, M.; TRINDADE, Z. Representações e práticas sociais: contribuições teóricas e dificuldades metodológicas. Temas psicol., Ribeirão Preto, v. 8, n. 3, p. 257-267, dez. 2000. Disponível em: http://pepsic.bvsalud.org/scielo.php?script=sci_arttext\&pid=S1413389X2000000300005\&lng=pt\&nrm=iso. Acesso em : 15 maio 2020.

ALTET, M. As competências do professor profissional : entre conhecimentos, esquemas de ação e adaptação, saber analisar. In : PAQUAY, L. et al. Formando professores profissionais. Porto Alegre: Artmed, 2001. (p. 23-35).

ALTET, M. A observação das práticas de ensino efetivas em sala de aula: pesquisa e formação. Cadernos de Pesquisa, v.47 n.166 p.1196-1223 out./dez. 2017.

ALTET, M. Caractériser, expliquer et comprendre les pratiques enseignantes pour aussi contribuer à leur évaluation. Les dossiers dessciences de l'éducation, n. 10, p. 31-43, 2003.

BAKHTIN, M. Os gêneros do discurso. Org., Trad., Posfácio e Notas: Paulo Bezerra. São Paulo: Editora 34, 2016. 164p.

BARBOSA, M. A. Dicionário, Vocabulário e Terminologia: concepções. In: ALVES, Ieda Maria. (Org.). A Constituição da Normalizạ̧ão Terminológica no Brasil. 2. ed. São Paulo: FFLCH/CITRAT, 2001. (Cadernos de Terminologia, n. 1, p. 17-45).

BARROS, J. A. Os conceitos: seus usos nas Ciências Sociais. Petrópolis: Vozes, 2016.

BOURDIEU, P. Para uma sociologia da ciência. Porto: Edições 70, 2001.

BOURDIEU, P.; CHAMBOREDON, J. C.; PASSERON, J. C. A profissão de sociólogo. sociológico. Petrópolis: Vozes, 1998.

CAMBI, F. História da Pedagogia. São Paulo: UNESP, 1999.

CAMPOS, P. A abordagem estrutural e o estudo das relações entre práticas e representações sociais. In: CAMPOS, P.; LOUREIRO, M. (Orgs.). Representações sociais e práticas educativas. Goiânia: UCG, 2003. p. 21-36.

CHARLOT, B. Da relação com o saber às práticas educativas. São Paulo: Cortez, 2014. 
CHARLOT, B. Da relação com o saber: elementos para uma Teoria. Porto Alegre: Artmed, 2000.

DUPRIEZ, V.; CHAPELLE, G. Enseigner. Paris: Presses Universitaires de France, 2007.

FAUCHEUX, C.; MOSCOVICI, S. Observaciones criticas sobre la "cuestion microsocial". MORIN, E. (Org.). Psicologia socialy compromiso político. Buenos Aires: Rodolfo Alonso Editor, 1971. p. 54-76.

FRANCO, M. A. R. S. Pedagogia e prática docente. São Paulo: Cortez, 2012.

FREIRE, P. Educação como prática da liberdade. São Paulo: Paz e Terra, 2018.

FREIRE, P. Pedagogia da autonomia. São Paulo: Paz e Terra, 1996.

FREIRE, P. Pedagogia da esperança. São Paulo: Paz e Terra, 2011.

FROMM, G. Obras lexicográficas e terminológicas: definições. Revista Factus, Taboão da Serra, v. 1, n. 2, p. 139-147, 2004.

GAUTHIER, C.; TARDIF, M. A pedagogia: teorias e práticas da antiguidade aos nossos dias. 3. ed. Petrópolis: Vozes, 2014.

GIMENO SACRISTÁN, J. G.; PEREZ GOMÉZ. A. I. Compreender e transformar o ensino. 4. ed. Porto Alegre: Artmed, 1998.

HADJI, C.; BAILLÉ, J. Recherche et éducation, vers une «nouvelle alliance ». Bruxelles: De Boeck, 1998.

JODELET, D. Loucuras e Representações Sociais. Petrópolis: Vozes, 2005.

JODELET, D. Représentation sociale. In: MOSCOVICI, S. (Org.). Psychologie social. Paris: Presses Universitaires de France, 1984. p. 357-378.

JODELET, D. Représentations sociales: un domaine en expansion. In: JODELET, D. (Org.). Les représentations sociales. Paris: Presses Universitaires de France, 1989.

JODELET, D. O movimento de retorno ao sujeito e a abordagem das representações sociais. Soc. Estado, Brasília, v. 24, n. 3, p. 679-712, dez. 2009. DOI: https://doi.org/10.1590/S0102-69922009000300004.

KOSELLECK, R. Estudos Históricos, Rio de Janeiro, v. 5, n. 10, p. 134-146, 1992.

LAHLOU, S. La modélisation de représentations sociales à partir de l'analyse d'un corpus de définitions. In: MARTIN, E. (Ed.). Informatique textuelle. Paris: Didier, 1996. p. 55-98.

LATOUR, B. Sur la pratique des théoriciens. In: BARBIER, J.-M. Savoirs théoriques et savoirs d'action. Presses Universitaires de France, 2011. p. 131-146.

LIBÂNEO, J. C. Pedagogia e pedagogos, para quê? São Paulo: Cortez, 1998.

LIMA, R. C. P.; SANTOS, I. S. Representações sociais e práticas em escolas do ensino fundamental: efeitos de unidades de polícia pacificadora (UPP) no Rio de Janeiro. Psicologia e saber social, v. 6, p. 67-86, 2017. 
MANACORDA, M. A. História da educação: da antiguidade aos nossos dias. São Paulo: Cortez, 2010.

MEIRIEU, P. A pedagogia ente o dizere e o fazer. Porto Alegre: Artmed, 2008.

PAQUAY, L. et al. Formando professores profissionais. Porto Alegre: Artmed, 2001.

PERRENOUD, P. A prática reflexiva no oficio do professor. Porto Alegre: Artmed, 2002.

PERRENOUD, P. O trabalho do habitus na formação de professores. In: PAQUAY, L. et al. Formando professores profissionais. Porto Alegre: Artmed, 2001. p. 161- 183.

PIMENTA, S. G. Apresentação da coleção. In: CHARLOT, B. Da relação com o saber às práticas educativas. São Paulo: Cortez, 2012.

PIMENTA, S. G. Formação de professores: identidade e saberes da docência. In: PIMENTA, S. G. (Org.). Saberes pedagógicos e atividade docente. São Paulo: Cortez, 1999. (p. 15$34)$.

PIMENTA, S. G.; GHEDIN, E. (Orgs.). Professor Reflexivo no Brasil: gênese e crítica de um conceito. São Paulo: Cortez, 2002.

ROUQUETTE, M. L. Representações e Práticas Sociais: alguns elementos teóricos. In: MOREIRA, A. S. P.; OLIVEIRA, D. C. (Orgs.). Estudos Interdisciplinares em Representações Sociais. Goiânia: AB Editora, 1998. p. 39-46.

SÁ, C. P. Sur les relations entre représentations sociales, pratiques socio-culturelles et comportement. Papers On Social Representation, v. 3, n. 1, p. 40-46, 1994.

SAVIANI, D. Histórias das ideias pedagógicas no Brasil. São Paulo: Editores Associados, 2018.

SCHÖN, D. Educando o Profissional Reflexivo: Um novo design para o ensino e a aprendizagem. Porto Alegre: Artmed, 2003.

TARDIF, M. Saberes Docentes \& Formação Profissional. Petrópolis: Vozes, 2002.

WOLTER, R.; SÁ, C. As relações entre representações e práticas: o caminho esquecido... Revista Internacional de Ciencias Sociales y Humanidades, v. 33, p. 87-105, 2013.

YAMAMOTO, O. H. A Educação Brasileira e a Tradição Marxista: 1970-90. Natal: EDUFRN, 1996.

\section{Fontes}

ANTUNES, C. Glossário para Educadores(as). Petrópolis: Vozes, 2001.

ARENILLA, L. et al. Dicionário de pedagogia. 2. ed. rev. e aument. Lisboa: Instituto Piaget, 2013.

CALDART, R. S. et al. (Orgs.). Dicionário da Educação do Campo. Rio de Janeiro, São Paulo: Escola Politécnica de Saúde Joaquim Venâncio, Expressão Popular, 2012.

CALDEIRA, A. M. S.; ZAIDAN, S. Prática pedagógica. In: OLIVEIRA, D. A.; DUARTE, A. M. C.; VIEIRA, L. M. F. Dicionário: trabalho, profissão e condição docente. Belo 
Horizonte: UFMG/Faculdade de Educação, 2010. CDROM Disponível na internet em: http://gestrado.net.br/pdf/328.pdf Acesso em: 15 maio 2020.

DUARTE, S. G. Dicionário Brasileiro de Educação. Rio de Janeiro: Edições Antares, Nobel, 1986.

FOULQUIÉ. Dicionário da Lingua Pedagógica. Lisboa: Livros Horizonte, 1971.

LUZ, G. Prática Pedagógica. In: SOUZA, J.; GUERRA, R. Dicionário Crítico de Educação. Belo Horizonte: Dimensão, 2014.

MOROSINI, M. C. Glossário. In: MOROSINI, M. C. (Org.). Enciclopédia de Pedagogia Universitária. Porto Alegre: FAPERGS/RIES, 2003. (p. 295-434).

MOROSINI, M. C. Glossário. In: MOROSINI, M. C. (Org.). Enciclopédia de Pedagogia Universitária. Glossário, v. 2. Brasília: INEP/RIES, 2006.

PEREIRA, I. B.; LIMA, J. C. F. Dicionário da educação profissional em saúde. 2. ed. rev. ampl. Rio de Janeiro: EPSJV, 2008.

QUEIROZ, T. D. Dicionário Prático de Pedagogia. São Paulo: Rideel, 2011.

STRECK, D. R.; REDIN, E.; ZITKOSKI, J. Dicionário Paulo Freire. Belo Horizonte: Autêntica, 2008.

VASCONCELOS, M. L.; BRITO, R. H. P. Conceitos de educaşão em Paulo Freire: glossário. Rio de Janeiro: Vozes; São Paulo: Mack Pesquisa, 2014.

ZANTEN, A. Dicionário de Educação. Petrópolis, Vozes: 2011.

RECEBIDO: 08/06/2020

APROVADO: $28 / 07 / 2020$

RECEIVED: 06/08/2020

APPROVED: 07/28/2020

RECIBIDO: $08 / 06 / 2020$

APROBADO: $28 / 07 / 2020$ 